\title{
Screening for oligonucleotide binding affinity by a convenient fluorescence competition assay
}

\author{
Joseph G. Harrison, Xiaohai Liu and Shankar Balasubramanian* \\ University Chemical Laboratory, Cambridge University, Lensfield Road, Cambridge CB2 1EW, UK
}

Received May 5, 1999; Revised and Accepted July 8, 1999

\begin{abstract}
A competitive homogeneous quenched fluorescence assay system is described for the high throughput screening of DNA conjugates that bind to singlestranded DNA. Fluorescence signal is generated by competitive binding of the sample molecule to a target strand labelled with a quencher probe, which is otherwise hybridised to a complementary strand containing a fluorescent probe. Thus fluorescence generated is related to the affinity of the sample. Competitive analysis of a number of peptideoligonucleotide conjugates gave data that correlated well with the corresponding UV melting data. The assay will be useful for screening of large numbers of potential single-stranded binding molecules.
\end{abstract}

\section{INTRODUCTION}

Oligonucleotide conjugates have become important in the field of therapeutic oligonucleotides for enhancing cellular uptake, targeting specific cell types and increasing target binding affinity. Derivatives and conjugates of oligonucleotides with altered hybridisation properties may also have an important role to play as probes in the field of genetic analysis which is growing in importance. We and others have been exploring combinatorial approaches to generating oligonucleotides or oligonucleotide conjugates with a view to a hybridisationbased screening for molecules with enhanced target binding properties. For large libraries of more than 100 compounds melting temperature analysis is slow and impractical. There are a number of examples in the literature of fluorescence-based methods to study nucleic acid hybridisation that include detection by fluorescence resonance energy transfer (1) (FRET), 'molecular beacons' for the detection of specific hybridisation (2) and quantitation of PCR-amplified DNA (3), and the use of fluorescently-labelled nucleic acids to detect hybridisation on genechips $(4,5)$. We have studied a simple, quenched-fluorescence assay for the semi-quantitative analysis of oligonucleotide conjugates or other molecules that could be adapted to a 96-well (or higher density) parallel format.

The basis for the proposed assay system is presented in Figure 1. A target oligonucleotide with a suitably positioned fluorescent quenching probe (A) is initially hybridised to a complementary oligonucleotide carrying a fluorescent probe (B). In this duplex any fluorescence generated upon excitation will be substantially quenched. If a molecule $\mathrm{C}$ that competes for binding to target $\mathrm{A}$ is added, and the system allowed to equilibrate, then competitor $\mathrm{C}$ will replace $\mathrm{B}$ liberating fluorescence in the solution. The level of fluorescence liberated should reflect the proportion of $\mathrm{A}$ bound to $\mathrm{C}$ and hence the affinity which $\mathrm{C}$ has for target $\mathrm{A}$. In principle it should be possible to tune the assay to screen for competing molecules (C) of different affinities by varying the extent of overlap between components $\mathrm{A}$ and $\mathrm{B}$.

\section{MATERIALS AND METHODS}

Oligonucleotides were purchased from Oswel DNA Service (Southampton, UK) and fluorophores from Molecular Probes Inc. All other chemicals were from Sigma.

HPLC was carried out on a reverse phase Hewlett Packard Spherisorb ODS $2.5 \mu \mathrm{m}$ column on a Hewlett Packard series 1100 system. Mobile phase A was $0.1 \mathrm{M}$ ammonium acetate $(\mathrm{pH} 7.0)$ and mobile phase B was HPLC grade acetonitrile. The gradients used were: gradient 1: 0-5 min, isocratic 5\% B; 5-30 min, 5-30\% B; 30-35 min, isocratic 30\% B; 35-40 min, 30-100\% $\mathrm{B}$; 40-43 min, isocratic $100 \% \mathrm{~B}$; 43-45 min, 100-5\% B.

Electrospray mass spectrometry was carried out using a VG Bio-Q quadrupole mass spectrometer and all data were acquired and analysed using MassLynx software.

Synthesis of the TAMRA-derivatised 16mer (T16)

To a solution of propargyl amino dU-modified 16mer (1) (Oswel DNA Service) in water $(100 \mu \mathrm{l}, 24.4 \mathrm{nmol})$ was added $0.1 \mathrm{M}$ sodium phosphate $(\mathrm{pH} 8.2)(300 \mu \mathrm{l})$ and a solution of 5(and 6)-carboxytetramethylrhodamine $N$-hydroxysuccinimide ester (TAMRA-NHS), mixed isomers, $(\sim 0.5 \mathrm{mg}, 1 \mu \mathrm{mol})$ in $N, N$-dimethylformamide (DMF) $(50 \mu \mathrm{l})$. The reaction was left to proceed for $2 \mathrm{~h}$ before addition of another aliquot of the fluorophore $(\sim 0.5 \mathrm{mg})$ in DMF $(50 \mu \mathrm{l})$ and incubation for a further $60 \mathrm{~min}$. The solution was then made up to $1 \mathrm{ml}$ with water and the oligonucleotide products were purified by gel filtration through a NAP 10 column. The eluant was concentrated to dryness in vacuo and redissolved in water $(100 \mu \mathrm{l})$. Analysis of a sample of this solution $(2 \mu \mathrm{l}, 0.5 \mathrm{nmol})$ by reverse phase HPLC indicated that the reaction had proceeded in $86 \%$ yield (62\% 6-isomer, 24\% 5-isomer) by peak area. Preparative scale HPLC was carried out on the remaining solution and both product isomers were collected separately, dried in vacuo, redissolved in water $(100 \mu \mathrm{l})$, quantitated by $\mathrm{A}_{260}$ (total collected yield $16.9 \mathrm{nmol}, 70 \%$ ) and stored at $-20^{\circ} \mathrm{C}$. 


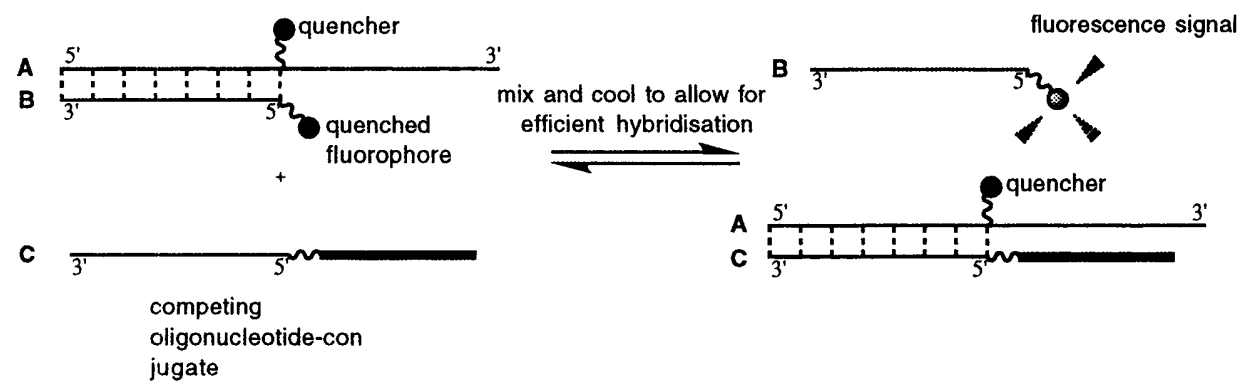

Figure 1. Components for competition assay.

6-isomer (11.1 nmol, 46\%): analytical reverse phase HPLC $\mathrm{t}_{\mathrm{R}}: 17.1 \mathrm{~min} ; \mathrm{m} / \mathrm{z}$ (negative mode ESMS) mass found 5260.5 $\left([\mathrm{M}-\mathrm{H}]^{-}\right)$, calculated 5260.3.

5-isomer (5.8 nmol, 24\%): analytical reverse phase HPLC $\mathrm{t}_{\mathrm{R}}$ : $17.9 \mathrm{~min} ; \mathrm{m} / z$ (negative mode ESMS) mass found $5260.8\left([\mathrm{M}-\mathrm{H}]^{-}\right)$, calculated 5260.3.

\section{UV spectroscopic analysis of modified oligonucleotides}

The modified oligonucleotides were also characterised by UV spectroscopy to determine if attachment to an oligonucleotide altered the spectral properties of the fluorophores. Stock solutions of both conjugates were made up in $10 \mathrm{mM}$ sodium phosphate (pH 7.0), 0.1 M NaCl and 0.1 mM EDTA buffer [5'fluorescein $8 \mathrm{mer}$ (F8) (4 $\mu \mathrm{M})$, 6-TAMRA 16mer (T16) $(7.8 \mu \mathrm{M})]$. The concentrations of these stock solutions were determined by $A_{260}$ using extinction coefficients $\left(\varepsilon_{260}\right)$ that included the absorbance of the fluorophore at $260 \mathrm{~nm}$. The contributions of the fluorophores to $\varepsilon_{260}$ were calculated by obtaining UV scans of the unconjugated probes fluorescein, and TAMRA-NHS, and obtaining the ratio of the absorbance at $260 \mathrm{~nm}$ to the absorbance at the maximum for each probe (497, 544 and $454 \mathrm{~nm}$ respectively). An $\varepsilon_{260}$ value for each probe was then calculated by multiplying these ratios with the known $\varepsilon_{\lambda \max }$ values.

\section{Melting temperature $\left(T_{\mathrm{m}}\right)$ studies}

Melting studies were carried out in stoppered $1 \mathrm{~cm}$ pathlength quartz cells on a computer-interfaced Varian Cary $1 \mathrm{E}$ UV-visible spectrophotometer at $260 \mathrm{~nm}$. Samples consisted of a $2 \mu \mathrm{M}$ concentration of each oligonucleotide in $1 \mathrm{ml}$ buffer composed of $10 \mathrm{mM}$ sodium phosphate ( $\mathrm{pH} 7.0), 0.1 \mathrm{M} \mathrm{NaCl}$ and $0.1 \mathrm{mM}$ EDTA. All samples were annealed by heating at $90^{\circ} \mathrm{C}$ for 5 min before cooling to $5^{\circ} \mathrm{C}$ by placing in a refrigerator for $1 \mathrm{~h}$. The melting curves were measured using a temperature gradient from 5 to $90^{\circ} \mathrm{C}$ with a ramp rate of $1{ }^{\circ} \mathrm{C} / \mathrm{min}$. The cuvettes were kept under dry nitrogen to prevent water condensation at low temperature. Analysis was carried out using the Varian Thermal software and $T_{\mathrm{m}}$ values were calculated using the first derivative method. Uncertainty in the $T_{\mathrm{m}}$ data obtained was estimated at $\pm 0.5^{\circ} \mathrm{C}$ based on repetitions of experiments.

\section{Fluorescence quenching competition assay for peptide- oligonucleotide conjugates}

Only the 6-isomer of the TAMRA 16mer (T16) was employed in this assay. All samples were made up in individual wells of 96-well plates in a total volume of $50 \mu 110 \mathrm{mM}$ sodium phosphate (pH 7.0), $0.1 \mathrm{M} \mathrm{NaCl}$ and $0.1 \mathrm{mM}$ EDTA. Concentrations of individual oligonucleotides in the final assay solutions ranged from 0.5 to $3 \mu \mathrm{M}$. Stock solutions of the oligonucleotides and peptide-oligonucleotide conjugates were made up in $10 \mathrm{mM}$ sodium phosphate $(\mathrm{pH} 7.0), 0.1 \mathrm{M} \mathrm{NaCl}$ and $0.1 \mathrm{mM}$ EDTA $(500 \mu \mathrm{l})$ and stored at $-20^{\circ} \mathrm{C}$ until required.

In a typical hybridisation experiment, the target 16mer (with or without fluorophore modification) was added to the wells first, followed by the 5 '-fluorescein 8 mer $(\mathbf{F 8})$. For wells in which competition was studied, the competing peptideoligonucleotide 8 mer was added next and the final volumes of all wells were made up to $50 \mu \mathrm{l}$ with $10 \mathrm{mM}$ sodium phosphate (pH 7.0), 0.1 M NaCl and 0.1 mM EDTA. The plate was then wrapped in aluminium foil to exclude light and left at room temperature for $30 \mathrm{~min}$. After this time, the plate was incubated at $4^{\circ} \mathrm{C}$ for $30 \mathrm{~min}$ before rapid transfer to a Molecular Dynamics Vistra fluorimager. The plate was scanned through a $530 \mathrm{~nm}$ band pass filter (20 nm band width) at a PMT voltage of $600 \mathrm{~V}$ in single scan mode. The image was collected and analysed using Image Quant software. Volume integrations were carried out on each well to quantitate the fluorescent signal.

\section{Time dependence binding studies of peptide- oligonucleotide (5R8)}

Seven sets of experiments (each with different incubation periods at $4^{\circ} \mathrm{C}$ ) were carried out with individual plates. The experimental procedure was as described above, but using final concentrations of $0.5 \mu \mathrm{M}$ F8, $1 \mu \mathrm{M}$ T16 and $2 \mu \mathrm{M}$ of competing peptideoligonucleotide conjugate 5R8. For each experiment the individual plate was incubated at $4^{\circ} \mathrm{C}$ for different periods of time $(5,10,20,30,40,55$ and $72 \mathrm{~min})$ immediately prior to measurement of fluorescence.

\section{RESULTS AND DISCUSSION}

To explore the assay we have employed a target 16mer deoxyoligonucleotide containing an internal deoxyuridine (dU) residue bearing a C-5 propargyl amino group (Oswel DNA services, UK) (1) and a competing 5'-fluorescein-modified 8mer deoxyoligonucleotide (Oswel DNA services, UK) (F8):

$\begin{array}{ll}\mathbf{F} 8 & \text { 5'-ATCACATUACACCTAG-3' } \\ \text { 3'-TAGTGTAA-5' }\end{array}$

(Bold indicates sites of modification.) 
Oligonucleotide 1 (in $0.1 \mathrm{M} \mathrm{NaPi}, \mathrm{pH}$ 8.2) was coupled to TAMRA-NHS (mixed isomers) and purified by HPLC. The identity of the resulting TAMRA-labelled 16mer (T16) was confirmed by electrospray mass spectrometry. The absorption spectrum of TAMRA has significant overlap with the emission spectrum of fluorescein, hence its choice as a suitable quencher. The sites of modification on both oligonucleotides were chosen to position the quencher (TAMRA) in close proximity to the fluorescein moiety in the hybridised duplex for significant quenching, which is in part inversely related to distance between the two probes. The UV properties of fluorescently-modified and unmodified oligonucleotides were characterised by UV spectroscopy. The resulting $\varepsilon_{260}$ values [in $\mathrm{dm}^{3}$ $\left.\mathrm{mol}^{-1} \mathrm{~cm}^{-1}\left(\times 10^{3}\right)\right]$ for each oligonucleotide were as follows: unmodified 8mer [3'-TAGTGTAA-5'] (86.4), 5'-fluorescein 8mer (F8) (101), propargyl amino dU 16mer (1) (175.8) and 6TAMRA 16mer (T16) (193.8). To ascertain whether the attachment of the fluorophores affected the hybridisation properties of the oligonucleotides, melting temperature studies were carried out (Table 1). The presence of the fluorescein modification alone slightly destabilised duplex formation relative to the unmodified $8 \mathrm{mer} / 16 \mathrm{mer}$ duplex. Interestingly, the F8/T16 duplex had an elevated $T_{\mathrm{m}}$. This extra stability possibly derived from a $\pi$-stacking interaction between the two fluorophores. These slight perturbations in $T_{\mathrm{m}}$ were not considered to be a problem for the requirements of the assay.

Table 1. Melting temperatures for the fluorophore-modified oligonucleotides $^{\mathrm{a}}$

\begin{tabular}{ll}
\hline Duplex & $T_{\mathrm{m}}\left({ }^{\circ} \mathrm{C}\right)$ \\
\hline Unmodified 8mer/16mer & 19.5 \\
F8/propargyl amino 16mer (1) & 18.9 \\
F8/T16 & 21.8 \\
\hline
\end{tabular}

a2 $\mu \mathrm{M}$ concentration of each oligonucleotide in $1 \mathrm{ml}$ of

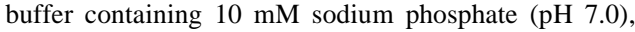
$0.1 \mathrm{M} \mathrm{NaCl}$ and $0.1 \mathrm{mM}$ EDTA. Temperature ramp rate was $1^{\circ} \mathrm{C} / \mathrm{min}$.

Fluorescence assays were carried out on a Vistra Fluorimager (Molecular Dynamics) with excitation of samples in a 96-well plate with an argon laser at $488 \mathrm{~nm}$, through a $530 \mathrm{~nm}$ band pass filter ( $20 \mathrm{~nm}$ band width) and the total fluorescence collected from each well quantified using ImageQuant software. Measurements were carried out for samples in $10 \mathrm{mM}$ $\mathrm{NaPi}(\mathrm{pH} 7.0), 0.1 \mathrm{M} \mathrm{NaCl}$ and $0.1 \mathrm{mM}$ EDTA that were first incubated for $30 \mathrm{~min}$ at ambient temperature, then at $4^{\circ} \mathrm{C}$ for $30 \mathrm{~min}$ (both in the dark). Defining the fluorescence emission observed from a $1 \mu \mathrm{M}$ solution of $\mathbf{F 8}$ as $100 \%$, the corresponding fluorescence from a $1 \mu \mathrm{M}$ solution of T16 alone was $<5 \%$. Interestingly, $\mathbf{F 8}$ was quenched to $85 \%$ when hybridised to the unlabelled propargyl amino dU 16mer (1) consistent with similar reported observations of fluorescence quenching on duplex formation (1). A sample of $1 \mu \mathrm{M} \mathrm{F8}$ plus $1 \mu \mathrm{M}$ T16 resulted in a decreased fluorescence signal of $40 \%$ which further reduced to 18 and $12 \%$ on increasing the $\mathbf{T 1 6}$ concentration to 2 and $3 \mu \mathrm{M}$ respectively indicating the design of the system was suitable for efficient quenching.

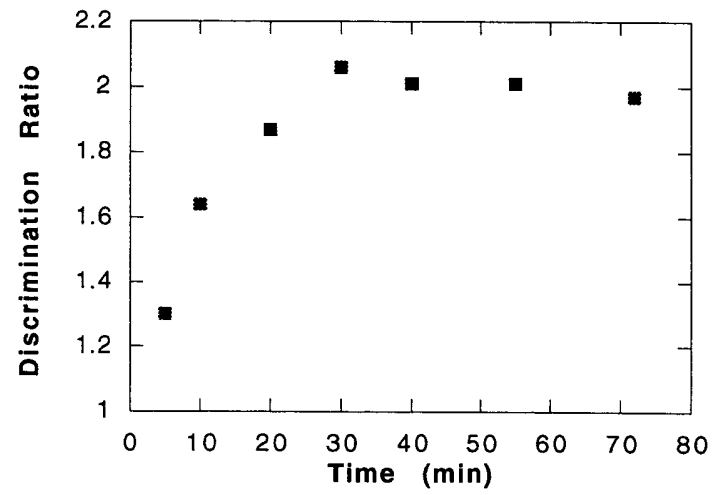

Figure 2. Variation of discrimination ratio with time for $5 \mathrm{R} 8$.

Competition experiments were carried out to assess the relative binding affinity of a number of cationic peptide-oligonucleotide conjugates prepared as described previously (6). The peptideoligonucleotide conjugates were generally of the form:

$2 \mathrm{X} 8=5^{\prime}-A A A X X A C-8 \mathrm{mer}$

$3 \mathrm{X} 8=5^{\prime}-A A X X X A C-8 \mathrm{mer}$

$4 \mathrm{X} 8=55^{\prime}-A X X X X A C-8 \mathrm{mer}$

$5 \mathrm{X} 8=5$ '- $-A X X X X X C-8 \mathrm{mer}$

where 8 mer refers to the deoxyoligonucleotide 3'-TAGTGTAA-5' and $X$ is one of the amino acids: lysine $(\mathrm{K})$, arginine $(\mathrm{R})$, ornithine $(\mathrm{O})$ or histidine $(\mathrm{H})$, and $A$ and $C$ are alanine and cysteine respectively.

To study the assay T16 was generally first added to a microplate well, followed by the addition of $\mathbf{F 8}$ and then the competing molecule (designated C, Fig. 1). The plate was left in the dark for $30 \mathrm{~min}$ at ambient temperature $\left(20^{\circ} \mathrm{C}\right)$, then at $4^{\circ} \mathrm{C}$ in the dark for a further $30 \mathrm{~min}$ before rapid transfer to the fluorimager for fluorescence quantitation. In order to evaluate peptideoligonucleotide conjugates, we have defined a discrimination ratio which is indicative of the contribution of the peptide portion towards binding. The discrimination ratio is defined as the $\%$ fluorescence signal generated in the presence of the competing peptide-oligonucleotide (e.g. 5K8) divided by the $\%$ fluorescence signal generated by competing unmodified 8 mer at the same concentration. The discrimination ratio for the system was found to be sensitive to the relative concentrations of oligonucleotides (Table 2a). It was found that using final concentrations of $0.5 \mu \mathrm{M} \mathrm{F8}$ and $1 \mu \mathrm{M} \mathrm{T16}$ gave a system that gave only $23 \%$ fluorescence (i.e. was $77 \%$ quenched) relative to the fluorescence of $\mathbf{F 8}$ alone. A discrimination ratio of 1.94 was obtained for $0.5 \mu \mathrm{M} \mathrm{F8} / 1 \mu \mathrm{M}$ T8 with $2 \mu \mathrm{M} 5 \mathrm{~K} 8$ competitor (Table 2b). These relative concentrations were chosen as a convenient optimum for the system tested. The corresponding melting temperatures were measured to be $19.5^{\circ} \mathrm{C}$ for $8 \mathrm{mer} /$ $16 \mathrm{mer}$ (where both oligonucleotides are unmodified) and $29.2^{\circ} \mathrm{C}$ for $5 \mathrm{~K} 8 / 16 \mathrm{mer}$.

Under the conditions described for the assay the final incubation of samples at $4^{\circ} \mathrm{C}$ was shown to give rise to a timedependent variation in the recorded fluorescence. Figure 2 shows data from assays where the competitor is the conjugate 5R8 and the final incubation time is varied from 5 up to $72 \mathrm{~min}$. The fluorescence, which has been expressed as the 
Table 2a. Variation of discrimination ratio using $5 \mathrm{~K} 8$ as a competitor

\begin{tabular}{ll}
\hline Competition conditions & Discrimination ratio \\
\hline $1 \mu \mathrm{M} \mathrm{F8} / \mathrm{T16}+1 \mu \mathrm{M} \mathbf{5 K 8}$ & 1.69 \\
$1 \mu \mathrm{M} \mathrm{F8} / \mathrm{T16}+2 \mu \mathrm{M} \mathbf{5 K 8}$ & 1.46 \\
$1 \mu \mathrm{M} \mathrm{F8/T16}+3 \mu \mathrm{M} \mathbf{5 K 8}$ & 1.54 \\
$0.5 \mu \mathrm{M} \mathrm{F8} / \mathbf{T 1 6}+2 \mu \mathrm{M} \mathbf{5 K 8}$ & 1.94 \\
\hline
\end{tabular}

Table 2b. Optimised discrimination

\begin{tabular}{lllll}
\hline$[\mathbf{F 8}](\mu \mathrm{M})$ & {$[\mathbf{T 1 6}](\mu \mathrm{M})$} & Competitor & \% Fluorescence & Discrimination ratio \\
\hline 0.5 & - & - & 100 & - \\
0.5 & 1 & - & 23 & - \\
0.5 & 1 & $8 \mathrm{mer}, 2 \mu \mathrm{M}$ & 36 & 1 \\
0.5 & 1 & $5 \mathrm{~K} 8,2 \mu \mathrm{M}$ & 70 & 1.94 \\
\hline
\end{tabular}

discrimination ratio for comparison, increases with time to a maximum value close to 2.0 which shows no significant further increase beyond $25 \mathrm{~min}$ under the time frame of the experiment. This analysis suggests that the $30 \mathrm{~min}$ incubation time generally employed for the assays is time-point beyond which one can reasonable assume a stable fluorescence signal. However, one must be cautious of cases of competing molecules where the kinetics of binding are substantially different from the reference oligonucleotide.

To evaluate the assay system, the discrimination ratios for a range of oligonucleotide-peptide conjugates were determined with corresponding melting temperatures ranging from 22.9 to $31.3^{\circ} \mathrm{C}$ (Table 3 ). The data derived from the fluorescence assay show good correlation with the melting temperatures, with the discrimination ratio increasing in a stepwise manner with an increasing number of cationic residues in the peptide in accordance with expectation (6).

The pentalysine (5K8), pentaarginine (5R8) and pentaornithne (5O8) constructs all generated similar discrimination ratios with fluorescence signals of $65-70 \%$ of the signal observed for free F8, suggesting the potential to discriminate competing oligonucleotide derivatives of higher affinity than those tested here. Increasing the length of the complementary overlap in the quenched duplex system from 8 bases (for the F8/T16 system) and competitive binding by equilibration at a suitably higher temperature should permit the assay to be carried out with a view to selecting competitive binders to single-stranded nucleic acids with higher affinities.

Using this assay it should be possible to rapidly screen a large number of oligonucleotide conjugates for hybridisation with any target sequence of interest and select candidates that show the best target binding affinity in at least a semi-quantitative fashion. Such candidates may then be analysed by more quantitative methods such as melting temperature analysis. The assay may also be applicable for other classes of molecules that can bind to single-stranded nucleic acid of given sequence and opens up the way for the screening of combinatorial libraries.
Table 3. Analysis of peptide-oligonucleotide conjugates by fluorescence assay and melting temperature, presented in order of increasing discrimination ratio

\begin{tabular}{lll}
\hline $\begin{array}{l}\text { Competing } \\
\text { oligonucleotide }\end{array}$ & $\begin{array}{l}\text { Discrimination } \\
\text { ratio }^{\mathrm{a}}\end{array}$ & Melting temperature $\left.{ }^{\mathrm{o}}{ }^{\circ} \mathrm{C}\right)$ \\
\hline $8 \mathrm{mer}$ & 1.00 & 19.5 \\
$2 \mathrm{O} 8$ & 1.36 & 23.7 \\
$2 \mathrm{~K} 8$ & 1.46 & 23.0 \\
$5 \mathrm{H} 8$ & 1.53 & 22.9 \\
$3 \mathrm{~K} 8$ & 1.59 & 24.1 \\
$3 \mathrm{O} 8$ & 1.65 & 24.9 \\
$4 \mathrm{~K} 8$ & 1.76 & 27.0 \\
$4 \mathrm{O} 8$ & 1.83 & 27.7 \\
$5 \mathrm{~K} 8$ & 1.93 & 29.2 \\
$5 \mathrm{O} 8$ & 2.00 & 29.7 \\
$5 \mathrm{R} 8$ & 2.02 & 31.3 \\
\hline
\end{tabular}

${ }^{\text {a}}$ Reproducibility in measurements of discrimination ratio was generally within \pm 0.1 based on repeat experiments (see also supplementary material).

b2 $\mathrm{mM}$ concentration of each oligonucleotide in $1 \mathrm{ml}$ of buffer containing $10 \mathrm{mM}$ sodium phosphate $(\mathrm{pH} 7.0), 0.1 \mathrm{M} \mathrm{NaCl}$ and $0.1 \mathrm{mM}$ EDTA. Temperature ramp rate was $1^{\circ} \mathrm{C} / \mathrm{min}$.

\section{ACKNOWLEDGEMENTS}

We thank the MRC for a studentship (J.G.H.) and the BBSRC (Grant \# B08044). S.B. is a Royal Society University Research Fellow.

See supplementary material for additional experimental data from independent studies for comparison. 


\section{REFERENCES}

1. Cardullo,R.A., Agrawal,S., Flores,C., Zamecnik,P.C. and Wolf,D.E. (1988) Proc. Natl Acad. Sci. USA, 85, 8790-8794.

2. Tyagi,S. and Kramer,F.R. (1996) Nature Biotechnol., 14, 303-308.

3. Nazarenko,I.A., Bhatnagar,S.K. and Hohman,R.J. (1997) Nucleic Acids Res., 25, 2516-2521.
4. Lockhart,D.J., Dong,H.L., Byrne,M.C., Follettie,M.T., Gallo,M.V., Chee,M.S., Mittmann,M., Wang,C.W., Kobayashi,M., Horton,H. and Brown,E.L. (1996) Nature Biotechnol., 14, 1675-1680.

5. Schena,M., Shalon,D., Heller,R., Chai,A., Brown,P.O. and Davis,R.W (1996) Proc. Natl Acad. Sci. USA, 93, 10614-10619.

6. Harrison,J.G. and Balasubramanian,S. (1998) Nucleic Acids Res., 26, 3136-3145. 